\title{
El poema como cámara de espejos y caja de resonancia: (des)identificación de los lectores en dos obras de Jaime Huenún*
}

\section{The Poem as a Hall of Mirrors and a Resonance Chamber: Readers' (Des)identification in Two Works by Jaime Huenún}

MARTINA BORTIGNON

Departamento de Literatura

Universidad Adolfo Ibáñez

Diagonal Las Torres 2640 Peñalolén

Santiago, Región Metropolitana. Chile

martina.bortignon@uai.cl

Orcid ID 0000-0002-9774-8095

Resumen: El presente artículo se centra en las formas tanto textuales como performáticas relacionadas con la recepción lectora con que dos poemarios del autor mapuche Jaime Huenún -Puerto Trakl (2001) y Fanon City meu (2014)-, caracterizados por un consciente reenvío intertextual al acervo literario mundial, ponen en descubierto las dinámicas de identificación y des-identificación de sus lectores respecto a un horizonte cultural dominado por la perspectiva occidental. Para este efecto se abordarán los textos a partir de la reciente teoría del embodiment y del rol de las sensaciones en la fenomenología de la lectura, proponiendo un acercamiento crítico desde la proyección de imaginarios y desde el resonar de la voz. La hipótesis es que ambos poemarios, al funcionar como dispositivos materiales de reconocimiento de alianzas identitarias, llevarían finalmente al lector a leerse a sí mismo y a su horizonte cultural a contrapelo de los modelos identitarios que se tienden a proponer como dominantes en el circuito de consumo de la mismidad y la diferencia.

Palabras clave: Jaime Huenún. (Des)identificación. Lectura. Embodiment. Escucha.
RECIBIDO: 22 DE OCTUBRE DE 2016 ACEPTADO: 4 DE ENERO DE 2017

Abstract: This essay focuses on the textual and performative reader-bound strategies by which two works by the mapuche poet Jaime Huenún -Puerto Trakl (2001) y Fanon City meu (2014)-, characterized by an intended intertextual allusion to world literature tradition, uncover the dynamics of identification and des-identification of their readers with a cultural horizon dominated by a western perspective. To this end, the texts will be studied applying the embodiment theory and the role of perceptions in the phenomenology of reading, and a critical approach from the projection of imaginaries and from the sounding of voice will be used. My hypothesis is that both works, functioning as material devices for the recognition of identity alliances, would bring the reader to read herself and her cultural horizon against the grain of identity models that tend to be shown as dominant in the circuit of consumption of identity and difference.

Keywords: Jaime Huenún. (Dis)identification. Reading. Embodiment. Listening.

\footnotetext{
* Este artículo es un producto del Proyecto de Investigación Postdoctoral CONICYT Fondecyt n. 3140423: "La palabra sensible: lenguaje poético y sensaciones en obras chilenas e italianas contemporáneas", del que soy investigadora responsable.
} 
$\mathrm{D}$ entro de las diversas líneas temáticas en que se ha expresado la poesía mapuche en los últimos veinte años en Chile, Jaime Huenún representa la corriente mestiza. ${ }^{1}$ Esta vertiente poética, que cuenta con las voces de Bernardo Colipán, Juan Paulo Huirimilla, Roxana Miranda Rupailaf y Maribel Mora Curriao, entre otros, se caracteriza por trenzar la memoria y las expresiones culturales de ascendencia mapuche con las de origen occidental y por posicionar la literatura mapuche en el horizonte de la literatura mundial. Como destaca Maribel Mora Curriao dando razón de este proceso poético que evidencia la vocación cultural mestiza, este grupo de poetas "asume la poesía moderna y la condición de poeta para incorporar allí los elementos de su cultura propia a la que no han accedido libremente debido a los diversos procesos socio-históricos de dominación cultural, sino que en muchos casos solo a través de un proceso de recuperación" (331). Por su parte, el crítico Sergio Mansilla considera este proceso estético-cultural como uno de los más relevantes de la contemporaneidad latinoamericana, describiéndolo como "el ingreso de poetas de origen indígena al canon de la modernidad literaria, y no solo como voces «otras» atendibles por su singularidad «exótica» o por el estatus sacrificial que les daría el sufrimiento histórico del que han sido víctimas" (13). En particular, la condición mestiza de Jaime Huenún, que él mismo cataloga, utilizando un término de origen mapuche, como "champurria" (2015, 231), se refleja en un universo poético en donde diferentes identidades convergen o se forman bajo la presión de los factores históricos. A la vez, es típica de este autor la tensión metapoética y metarreflexiva, por lo cual las discursividades que quedan expuestas en sus versos apelan a poner en tela de juicio y eventualmente desmontar ciertas dinámicas naturalizadas de adhesión cultural e identitaria de los sujetos. La poesía de Huenún parte de una conciencia de la diferencia que afecta el territorio de lo vivencial y lo histórico para interrogar las zonas opacas y los puntos ciegos que habitan no solo el relato nacional, sino también los procesos de recepción de la expresión literaria mapuche y mestiza en un país, como lo es Chile, que con dificultad se reconoce fuera del estereotipo de sujeto blanco de origen europeo.

En este artículo, me interesa iluminar precisamente los modos textuales y performativos con que el poema, concebido como dispositivo literario e

1. Jaime Huenún (Valdivia 1967) es autor de Ceremonias (1999), Puerto Trakl (2001), Reducciones (2012) y La calle Mandelstam y otros territorios apócrifos (2016), además de varias antologías de poetas mapuche en versión bilingüe. 
ideológico, ${ }^{2}$ pone al descubierto las dinámicas de identificación y des-identificación de su lector respecto a un relato que se acerca a las identidades dominantes, tensando sin embargo la diferencia con la mismidad de manera productiva y nada ingenua. Para este efecto, revisaré dos poemarios del autor -Puerto Trakl (2001) y Fanon City meu (2014)-, caracterizados por un evidente reenvío intertextual al acervo literario mundial, a través de la lupa de la experiencia lectora, recibida en sus aspectos concretos e imaginativos que la reciente teoría del embodiment y de las sensaciones en la respuesta estética saca a luz. ${ }^{3}$ Tal experiencia de lectura aparecerá cruzada por las interrogantes y las contradicciones que surgen del hecho de poner bajo sospecha la posición de quien lee. Asumiré, dentro del espectro de posibles receptores que implica el acto de dirigirse desde la hibridez enunciativa, un público de adscripción identitaria occidental que lee la producción de Huenún con la curiosidad de encontrar en ella las marcas de su apertura al canon occidental. Mi propuesta es que ambos poemarios, al funcionar como dispositivos de reconocimiento de alianzas identitarias, llevarían finalmente al lector a leerse a sí mismo y a su horizonte cultural desde un punto de vista inusual para el sujeto, a contrapelo de los modelos identitarios que se tienden a proponer como dominantes en el circuito de consumo de la mismidad y la diferencia.

En particular, en relación con Puerto Trakl, analizaré la manera en que los repertorios literarios, según la definición que de ellos proporciona Wolfgang Iser en su ya clásica teoría de la respuesta estética, se conjugan con las recientes intuiciones de un cuerpo virtual del lector que exploraría el espacio imaginado y perceptivamente vivido del poema (Caracciolo 117). Esta alianza trans-

2. El poema vendría a ser un dispositivo no solamente literario sino también ideológico en el momento en que pone en tensión y contradicción interna justamente la ideología, es decir, el conjunto de ideas que el individuo, la sociedad o una época histórica determinada asume como herramienta para explicitar una visión del mundo y del ser humano. La eficacia de tal dispositivo, sin embargo, depende de la disposición del lector por dejarse condicionar por lo leído.

3. Se trata de una línea teórica que aborda el estudio de la narratología y de la fenomenología de la literatura a partir de la segunda generación de ciencias cognitivas, que comprende los procesos mentales a partir del cuerpo y sus formas de relacionarse con la realidad. Algunos de los textos fundacionales de esta nueva forma de teorizar la mente son los de Varela/Thompson/Rosch; Lakoff/Johnson; Damasio. Entre los muchos estudios que se han interesado en aplicar una mirada crítica atenta al embodiment y a las sensaciones en la lectura se pueden recordar: Syrotinski/Maclachlan; Zwaan; Bernini/Caracciolo. En general, este interés por lo corpóreo y las sensaciones surgió hace unos veinte años y se inserta, desde el punto de vista teórico, en un revival de la fenomenología encarnada del filósofo francés Maurice Merleau-Ponty, demostrando una notable vitalidad en diferentes ámbitos: filosofía, estudios de cine, crítica literaria, antropología, estudios de la voz, entre otros. 
forma el poema en una "cámara de espejos", ${ }^{4}$ en la cual el lector termina por visualizar y vivir como parte de su experiencia imaginativa un mundo perceptivo construido casi únicamente a partir de recuerdos y sugestiones procedentes de clásicos occidentales con los cuales se identifica usualmente. El lector es puesto en la condición de tomar conciencia del sistema de jerarquización y exclusiones que regula el canon literario mundial. Por otro lado, en una lectura de Fanon city meu enfocada en la dimensión material de lo sonoro en la escucha tanto mental del lector como aural de la voz del autor en el contexto de las lecturas públicas de su libro, se manifiesta una comprensión del poema como "caja de resonancia" para las voces múltiples y contradictorias que cohabitan en el texto. Los ecos que se generan en el dispositivo poético terminarían por visibilizar la contradicción inherente a la dinámica de identificación y des-identificación con la otredad, ${ }^{6}$ así como las implicaciones ínsitas en la acción de cruzar imaginativamente la línea del color, ${ }^{7}$ allí representada.

Se trata, como se ve, de dos acercamientos críticos complementarios, concebidos dentro de un horizonte teórico donde el fenómeno poético es indagado en su capacidad de generar una "mental imagery" (Kuzmičová) arraigada en lo corporal, no solamente a nivel textual sino a nivel de articulación fonatoria y recepción sonora del lenguaje literario. La aplicación a la poesía de Huenún de la vertiente perceptiva de la teoría de la respuesta estética en la lectura se demuestra particularmente pertinente también en la idea del poema como dispositivo ideológico que, incluso excediendo las hipotéticas intenciones autorales, trabaja en el corazón mismo de los mecanismos de proyección y adscripción identitaria de los lectores, evidenciando los equilibrios, todavía fuertemente marcados por el etnocentrismo, que afectan tanto la lectura como la cultura y la sociedad.

4. Con este término me refiero a las habitaciones en donde las paredes están cubiertas de espejos, generando un juego óptico de reflejos múltiples de un mismo cuerpo u objeto.

5. La caja de resonancia es una parte esencial de los instrumentos musicales, ya que permite que el sonido se amplifique y module, entregándole un timbre y color específico dependiendo de la tipología del instrumento y de los materiales. En este artículo, me refiero metafóricamente al poema como la caja de resonancia pensándolo en tanto dispositivo que, tal como sucede con los instrumento, da forma a las voces explícitas o potenciales del poema y sus matices, y las resalta.

6. Con el término "otredad" me refiero a la visión de individuos o comunidades humanas como diferentes y ajenas a la individualidad o al grupo humano de adscripción del sujeto. La otredad y su relación con la mismidad es objeto de reflexión antropológica, sociológica, psicoanalítica y filosófica.

7. Con el término "línea del color" me refiero a la visibilización de las fronteras raciales en la pigmentación de la piel, lo cual, en Chile, coincide también con la división entre clase sociales. 
EL POEMA COMO CÁMARA DE ESPEJOS: REPERTORIOS LITERARIOS Y CUERPO

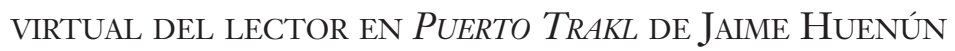

Sergio Mansilla señala que Huenún declaró cómo la composición de Puerto Trakl, una fantasmagoría marinera en que resuenan los clásicos occidentales como Rilke, Valéry y Melville, fue motivada por la intención de demostrar que "un poeta de origen mapuche perfectamente podía escribir un libro de poesía universal, instalarse en otro discurso y coordenadas literarias y no solo hacer alusión a su origen étnico" (Huenún 2004, cit. en Mansilla 14). En su artículo, Mansilla reporta que Iván Carrasco, uno de los críticos que interpretó el movimiento poético mapuche desde su surgimiento, suscribió con entusiasmo, y quizás sin mucho cuestionamiento, las palabras del poeta. Efectivamente, Carrasco escribió que en Puerto Trakl se hace presente

una poesía de características universales y ya clásicas, en la tradición de la poesía occidental, en la voz de un poeta mapuche-huilliche que se reconoce como tal, pero también incorpora la cultura formal, su saber poético, su lengua castellana y sus lecturas. (62, cit. en Mansilla 13)

La consecuencia implícita de esta visión crítica es que el manejo de referentes de la literatura universal pasó a ser, en la década del 2000, una suerte de "prueba" que los poetas indígenas tenían que "superar" para incorporarse con todo derecho a la poesía nacional y mundial; esto, en una dinámica que terminó por aplicar una mirada miope a la situación cultural real de los poetas de origen mapuche, quienes forman parte como cualquier otro poeta de un mundo globalizado y pueden, de la misma manera, valorar o distanciarse de los diferentes acervos literarios. En la perspectiva de la tesis que quiero proponer, el poemario de Huenún no se limita a "pasar la prueba" en la pugna por desmarcarse de los rótulos que se aplicaban a los autores indígenas al inicio del fenómeno literario protagonizados por ellos; quiero aventurar, por el contrario, que el dispositivo poético, aunque no sabemos si tal ha sido la intención expresa del autor, pone a prueba a aquel lector que podría estar basando su experiencia de lectura, entre otros elementos, en el hecho de averiguar cómo un poeta que se sitúa en el campo cultural a partir de su etnicidad y su mestizaje logra manejar satisfactoriamente modelos literarios validados por la tradición del hemisferio norte.

Es decir, el poemario funcionaría para el lector como una "cámara de espejos". En el momento en que el lector posiblemente se acerca con mirada 
exotizante a lo que piensa ser un producto literario que hibridiza lo étnico con la tradición occidental, pensando que con su lectura dará cuerpo a un microcosmos universalizante y local al mismo tiempo, el dispositivo del poema lo guía para que proyecte sucesivamente, en un telón vacío, su propio imaginario fundado en los clásicos europeos. A través de técnicas estéticas específicas que regulan la percepción lectora, el poemario permitirá que su lector, por una parte, se dé cuenta de la condición culturalmente marcada de su propio imaginario y, por la otra, vaya poniendo a prueba su propia competencia en su tradición de adscripción en el proceso de resolver el juego de las alusiones literarias.

POSICIONAMIENTO FÍSICO DEL LECTOR EN EL POEMARIO: ENTRE FOCALIZACIÓN ESTRECHA E INDETERMINACIÓN AMBIENTAL

El poemario se abre instalando una perspectiva subjetiva radicada en la primera persona singular y una focalización estrecha, interna al personaje. ${ }^{8} \mathrm{El}$ primer poema inicia así:

Bajé a Puerto Trakl entre neblinas.

Buscaba el bar de la buena suerte para charlar sobre la travesía.

Pero todos miraban la estrella polar en sus copas,

mudos como el mar frente a una isla desierta. (Huenún 2001, 5)

Según señala Caracciolo, quien estudia la respuesta lectora a la luz de la segunda generación de ciencias cognitivas y de la teoría del embodiment, el lector accede a la situación que está imaginando durante su lectura con un "cuerpo virtual”, en este caso coincidente con el del personaje principal del relato. Escribe Caracciolo: "The reader's virtual body [is] the counterpart of the real body the reader sends into fictional worlds in order to reconstruct fictional space" (117), y añade, basándose en los estudios empíricos en campo neurológico de Stephen Kosslyn, Giorgio Ganis y William Thompson: "The comprehension of a narrative passage triggers a mental simulation, usually in the form of mental imagery. According to the prevailing view, such imagery uses the same neuronal resources on which we draw for real perception" (119). Además, el cuerpo virtual del lector se va situando en el espacio imaginado del

8. Sobre la diferenciación narratológica entre focalización perceptiva cero, débil, ambiental, estrecha, ver el estudio de Manfred Jahn. 
puerto según las indicaciones que el texto provee, utilizando los "frames" a los cuales el lector está acostumbrado, es decir, la forma esperable en que se van presentando determinadas situaciones estereotípicas y la serie de sucesos que podrían estar asociadas con ellas (Minsky 211). La perspectiva del lector dentro del poemario coincide efectivamente con la de un personaje quien va vagabundeando por los bares de mala muerte y las callejuelas de un puerto brumoso: las expectativas en relación con la atmósfera imaginada y a los frames son bastante previsibles desde un principio. Sin embargo, es interesante notar cómo, en Puerto Trakl, el lector no cuenta con descripciones prolijas del entorno, lo cual denota una elección poética por parte del autor que determinaría, a su vez, unos efectos en la respuesta estética cuyos alcances pretendemos estudiar.

El lector, avanzando de un poema a otro, puede acceder, gracias al body tour (la sensación de estar físicamente y moverse en un lugar), a algunos espacios interiores del puerto, como las cantinas, cuyo ambiente es mantenido en un considerable nivel de vaguedad, siendo el alcohol el elemento más representado. Por otro lado, la interacción con el ambiente marino exterior es limitada, para el lector, al gaze tour (la sensación de ver un determinado panorama desde un punto fijo), aunque la vista finalmente es un sentido que resulta a menudo frustrado. "Muchos hombres han cruzado el océano / por un jarro de cerveza, por una copa / de ginebra caliente. [...] Escucha, solo escucha el estruendo del oleaje [...]" (7). El paisaje marino se hace presente por defecto, por medio de sustantivos lo suficientemente genéricos como para poder activar las más diversas proyecciones imaginativas; además, se refieren de por sí a lo no medible o circunscriptible -por ejemplo: "viento" (7), "nubes" (11), "pájaros" (11), "tiempo" (11)-. Hay, paralelamente, un vaciamiento del espacio, gracias a imágenes como "muelle desierto" (15), "isla desierta" (5), "la sal del horizonte" (27). En resumen, tanto el body tour como el gaze tour del cuerpo virtual del lector son mantenidos en sus mínimos términos perceptivos por el autor del poemario. Frente a tal elección compositiva, es pertinente interrogarse sobre cuáles serían las razones de esto en relación con la respuesta estética esperada y con el juego de las identificaciones del lector con el imaginario.

Podríamos aventurar una respuesta afirmando que la insistencia en el elemento del alcohol (en todas sus manifestaciones: del vino al whisky, pasando por el vodka), más que dar la tónica de la "cotidiana decadencia" (19) y de la deriva que experimenta quien llegue a este puerto, metaforiza la acti- 
vación, en el lector, de las fantasías marineras procedentes de la tradición literaria occidental, tal como el alcohol activa en los parroquianos del poemario alucinaciones y delirios. Tales rememoraciones literarias de ámbito marinero confluyen en el horizonte de "repertorios" posibles que el poemario convoca, siendo el "repertorio", según la definición que nos proporciona de ellos Wolfgang Iser en su teoría de la respuesta estética en la lectura, "all the familiar territory within the text. This may be in the form of references to earlier works, or to social and historical norms, or to the whole culture from which the text has emerged" (69). En este artículo, con el concepto de "repertorio" me referiré en particular al conocimiento, por parte del lector, de obras literarias anteriores y de referentes socioculturales. Mi propuesta es que estas fantasías se proyectarían en una pantalla en que solo aparecen pocos elementos marinos genéricos o brumosos que el cuerpo virtual del lector estaría observando en su gaze tour. La impresión de que el norte de la experiencia lectora sea el experimentar con las imaginaciones ligadas al repertorio literario de ámbito marinero de cada lector y no con su memoria de lugares concretos de un Chile sureño es confirmada por la insistencia en la esencia ficcional del puerto: "Sé que mi suerte no está / en ninguno de esos nimbos que regresan al mar / movidos apenas por el viento de la literatura" (11); "La noche llegó desde un poema de Trakl / que ella guardaba en la memoria" (19).

\section{PROYECCIÓN DE IMAGINARIOS LITERARIOS EN UN TELÓN VACÍO}

En la sensación de suspenso que el estatuto metaliterario produce al postular una circunstancia que depende del acto de poetar para concretarse, así como en el recurso poético del consumo de alcohol visto como facilitador de una vacilación perceptiva y mental, se anidan las alusiones a las obras literarias occidentales que el lector encuentra en su inmersión imaginativa y luego proyectará en el "telón de fondo" predispuesto por el poemario. Sin embargo, la proyección de tales antecedentes junto con su memoria imaginativa, emocional y perceptiva asociada depende de la capacidad de cada lector de reconocer, decodificar y recordar los referentes literarios mencionados. Puerto Trakl se va poblando de sensaciones y espacios imaginados a medida que el lector logra componer su propio mosaico de citas. El espacio de Puerto Trakl se forma, se expande y crece en relación directa con la competencia literaria del lector: en ese mismo lugar construido en base a los modelos proporcionados por las me- 
morias literarias, el lector envía su cuerpo virtual. Tales referencias pueden ser muy explícitas, como por ejemplo "Flores trajimos al cementerio marino" (33), obvio guiño a El cementerio marino de Paul Valéry; o más encubiertas, como el poema en el cual aparece un capellán amonestando a los marineros para que aparten el mal de sus vidas, recreación de uno de los capítulos iniciales de Moby Dick de Herman Melville. Además, hay textos que imitan la poética de algunos autores clásicos, funcionando muy bien como probable reescritura de poemas de Geroge Trakl o Rainer Maria Rilke (13). Finalmente, hay alusiones lo suficientemente amplias y sugerentes que pueden gatillar vínculos con algún que otro detalle de las obras de tema marinero de la tradición occidental: en el poema que empieza con los versos "Perdí mi idioma en la costa / ceniza de Trakl, dijo finalmente el polizón” (35) y sigue hablando de este clandestino que permaneció un tiempo en las bodegas de una nave, personalmente releo las aventuras del Gordon Pym de Edgar Allan Poe, quien lleva a su personaje desde las entrañas de una nave en la que se embarca clandestinamente hasta un Polo Sur alucinante donde, entre otras cosas, llueve una fina ceniza blanca sobre la balsa del protagonista.

De acuerdo a lo planteado por Marie-Laure Ryan, la inmersión perceptiva del lector en una obra es el resultado del "efecto madeleine": la mención de rasgos espaciales o perceptivos puntuales gatillaría, como lo hace el mordisco al famoso queque proustiano embebido en té, un conjunto de memorias personales que van componiendo los detalles de la escena imaginada (121). En la hipótesis aquí avanzada, la parquedad de las descripciones de los espacios físicos del puerto se aliaría con la prolijidad en las referencias literarias para favorecer la rememoración imaginativo-perceptiva para el lector. En particular, por una parte, la economía de detalles en las descripciones deja amplia libertad al lector para que acerque lo leído a su propia experiencia perceptiva y a su repertorio literario personal, inhibiendo la capacidad del texto de imponerle una figuración propia, novedosa y sorprendente, que lo saque de la zona de lo conocido. Por otra parte, aventuro que las referencias literarias que componen el repertorio que está en la base del poemario tienen un funcionamiento análogo a los nombres propios que designan ciertos lugares conocidos o deseados. Ryan describe de la siguiente manera el poder de los nombres propios de convocar una sensación de presencia y de encauzar proyecciones imaginativoafectivas:

The function of names is not to designate the properties of a certain object but to call its existence to the attention of the hearer, to impose it as 
discourse topic - in short, to conjure a presence to the mind. [...] Through this ability to tap into reservoirs of ready-made pictures, place names offer compressed images and descriptive shortcuts. (128)

Siguiendo el razonamiento de Ryan, las obras literarias mencionadas implícita o explícitamente en el texto de Huenún funcionarían como los nombres de ciudades famosas que catalizan el deseo y la imaginación de las personas, como París, Venecia, Viena, Nueva York. Así como una persona no necesita haber visitado París para poder asociar a esa ciudad determinadas connotaciones, como romanticismo, bohemia, sofisticación, los grandes clásicos de la literatura irradian un aura de seducción e invitan a una identificación a pesar incluso de que el lector no las haya leído.

Sobre esta base, se podría deducir que el texto está construido de manera que el lector pueda proyectar en completa libertad sus fantasías literarias e imaginativas. Sin embargo, esta misma saturación de presencias culturales occidentales puede guiar al lector a la toma de consciencia de la alineación etnocéntrica de sus referentes. Si, como se anticipó en la introducción, tomamos como referencia un modelo de lector con un buen conocimiento de la literatura del mundo occidental, interesado en encontrar en la producción de un autor mestizo como Huenún las marcas del diálogo entre este último y el canon occidental, podemos comparar Puerto Trakl con una cámara de espejos en los cuales se refleja la naturaleza culturalmente determinada de la imaginación de ese mismo lector, quien acaba proyectando y viviendo con su cuerpo virtual sus propias memorias literarias. Es preciso señalar que, en nuestra hipótesis, lo que hace del poema una cámara de espejos, es decir un pivote entre inmersión imaginativo-sensorial en el mundo que el lector construye a partir de las características de la obra artística y la toma de conciencia de que su experiencia es culturalmente e ideológicamente plasmada, es un efecto que funcionaría con este modelo de lector y puede no resultar tan evidente para otros. Sin embargo, una pista de que el mecanismo poético considera este efecto estético-ideológico dentro de sus posibilidades se puede encontrar en una explicitación, en los poemas de cierre, de la naturaleza potentemente metafórica de la obra, quedando de esta manera evidenciada, por parte de esta última, una intención alusiva a un orden de problemáticas culturales de vasto alcance.

Efectivamente, los poemas finales indican una voluntad de salir de un contexto cultural marcado por el pesimismo y el decadentismo, de un puerto connotado como "nublado y solitario, tenebroso y ficticio" (51): se deja aquí 
entender que tal espacio no es la única forma de comprender e imaginar la realidad, sino que la perspectiva occidental es una entre varias y posiblemente no la más vitalista.

Ebrio me despide Puerto Trakl con el alba mojando mi cabeza.

Sin dinero, sin amigos y sin reputación vuelvo a mis antiguos días.

La pequeña mañana abre sus puertas.

Los tugurios donde beben poetas y pescadores quedan para siempre atrás. (53)

Este poema revela que, después de tenderle una trampa a ese lector de adscripción cultural occidental a lo largo de toda la obra, el poema en tanto dispositivo ideológico-literario procede a enseñar sus mecanismos. Puerto Trakl ha activado alrededor de la idea de un puerto imaginado un juego de identificaciones que revelan la dificultad de salirse del círculo de la mismidad. La mayor parte, si no todas, de las alusiones literarias allí presentadas son reconducidas dentro del hemisferio boreal (véase la referencia a la estrella polar en varios poemas), ${ }^{9}$ es decir, en el poemario se exhibe el grado en que el imaginario se encuentra colonizado por la tradición occidental. Es en este punto donde podría intervenir la toma de conciencia que caracteriza las obras que trabajan a destiempo de su época:

The literary work [...] will serve to detach prevailing norms from their functional context, thus enabling the reader to observe how such social regulators function, and what effect they have on the people subject to them. The reader is thus placed in a position from which he can take a fresh look at the forces which guide and orient him, and which he may hitherto have accepted without question. (Iser 74)

Podríamos aventurar, así, que el poema pone al lector que tomamos como modelo en la condición de plantearse, junto con el hablante poético, la existencia de "Otra tierra [...] mejor que esta colina, / mejor que esta bahía donde muere la luz" (49); fuera de metáfora, la perspectiva de una mezcla más balanceada y compartida de repertorios perceptivos, culturales y artísticos diversos.

9. Sobre este detalle decisivo, ver Mansilla. 


\section{EL POEMA COMO CAJA DE RESONANCIA: FANON CITY MEU EN LAS VOCES} DEL AUTOR Y DEL LECTOR

$\mathrm{Al}$ leer el poemario Fanon City Meu, nos adentramos en una selva de cuerpos que exudan y vociferan, de colectividades sin líderes ni relatos, de comunidades porosas, mestizas, anti-higiénicas, por parafrasear unas reflexiones del autor sobre su obra. ${ }^{10}$ Ciudad Fanon es el vertedero de los sueños revolucionarios quemados y de las utopías socialistas fracasadas, el emplazamiento del destierro y de la deriva. El lector se queda atrapado en sus "calles circulares" (17), por las cuales deambulan y colisionan entre sí individuos y grupos alguna vez amparados por un proyecto "civilizador" y "humanizador", que finalmente los abandonó.

La obra propone claramente, a través de su título, las dos directrices según las cuales me parece que pretende ser leída. Por un lado, está la idea de un lugar concreto y cosmopolita: en mapudungún la preposición "meu" significa "en", mientras el uso de la palabra inglesa "city" complementa la idea de un crisol de razas y culturas allí asentadas. Es así como en Ciudad Fanon el lector encontrará un paisaje sonoro multilingüe de estruendos y murmullos, cánticos y plegarias, maldiciones y órdenes. Por otra parte, se declara la inscripción del proyecto poético en el nombre y la figura intelectual del teórico de la descolonización Frantz Fanon, cuya imagen aparece duplicada en la cubierta de la primera edición del libro: lo que se ve no es uno sino muchos Frantz Fanon, de diferentes colores y dimensiones. Es decir, no será la voz monocorde de un ideólogo que proclama sus consignas la que escucharemos resonar en la ciudad que lleva su nombre, sino la voz irónica, apasionada, poética, irreverente, cuestionadora, en fin, multitonal, del psiquiatra de Piel negra, máscaras blancas; una voz que se dedica a poner en tela de juicio los procesos psicológicos y sociológicos de identificación, desidentificación y alienación del hombre negro frente al hombre blanco. El estrato vocal que se deja escuchar en este punto, lejos de consolidar un discurso monolítico, da cabida al clamar del magma de las psiques cruzadas por su condición racial e histórica.

Se puede decir, entonces, que en el poemario Fanon City Meu Huenún construye algo así como un dispositivo de reverberación o una caja de resonancia: un artefacto poético-vocálico que permite, por una parte, conservar la

10. Conversación personal con el autor el 7 de julio de 2016. 
materialidad sensual, pensante y sufriente de las voces de zambos, mulatos, obreros, indios, guerrilleros, traficantes y fanáticos que acceden a él desde la historia, y, por la otra, dejar oír las variaciones y los ventriloquismos de la propia voz de Fanon, en el reenvío al hipotexto de Piel negra, máscaras blancas. Coherentemente con el enfoque propuesto en este trabajo, mantendré en análisis en el ámbito de los procesos corporales que entran en juego con la respuesta estética de los lectores, llevando la atención, ahora, al nivel verbal de la imaginación mental desencadenada por la literatura, como propone Anežka Kuzmičová en la misma línea de estudios de la Embodied Cognition: "Not only we process sentences [...] in ways largely resembling the situations they refer to, but we also process them in ways largely resembling the activity of reading them out loud or listening to them as spoken by somebody else" (277). ${ }^{11}$ A tal nivel imaginativo, me parece extremamente interesante añadir el ámbito de la recepción física de una voz real leyendo los poemas, siendo esta voz, en el caso analizado, la voz del autor mismo.

Es así como interrogaré el tránsito del coro disonante, plural, palinséstico que protagoniza el poemario de su dimensión virtual a su actualización en la voz de los lectores y del poeta mismo. Es decir, pondré en marcha la caja de resonancia que es Fanon City Meu relacionándola con la escucha mental de la voz de cada lector, que a pesar de ser muda no deja de ser fónica, y la escucha auditiva que ocurre en las performances del autor leyendo en voz alta sus poemas. Gracias a la puesta en contacto de tales niveles diversos de producción y recepción de la voz, se hará patente el juego de proyección/ identificación/ alienación recreado por Huenún para sus lectores a partir del texto de Fanon y de los discursos de tantos individuos anónimos.

\section{LA ESCUCHA DE LA VOZ SILENCIOSA DEL LECTOR}

Según afirma Garrett Stewarts, cada lector, en la lectura silenciosa que caracteriza la era moderna, "evocaliza”, es decir, evoca silenciosamente la voz leyendo en el locus físico de su cuerpo.

This somatic locus of soundless reception includes of course the brain but must be said to encompass as well the organs of vocal production,

11. Esta fuente teórica me ha sido señalada por uno de los revisores anónimos del artículo. Quiero expresar mi gratitud a ambos revisores anónimos por sus comentarios muy acertados que me ayudaron a enriquecer y mejorar mi texto. 
from diaphragm up through throat to tongue and palate. Silent reading locates itself, that is, in the conjoint cerebral activity and suppressed muscular action of a simultaneously summoned and silenced enunciation. (1)

Para Stewarts, la evocalización que ocurre en la lectura silenciosa se encuentra en permanente tensión entre la auralidad evocada y el límite anunciado de la vocalización oral: no es de ninguna manera un fenómeno puramente mental, sino que involucra los órganos fonatorios y las cavidades internas de resonancias del cuerpo del lector. El lector lee con el cuerpo a pesar de que no emita ningún sonido: en tanto lector también es performer. Además, si apelamos al concepto teorizado por Adriana Cavarero (13) de la voz como signo de unicidad y singularidad del sujeto, podemos afirmar que cada lector lee con su propia voz imaginada: una voz que no coincide exactamente con la que resuena cuando se emite, pero que tampoco se aleja demasiado de esta y que comparte sus rasgos esenciales (sexo, edad, timbre, particularidades de pronunciación individuales y geográficas, entre otros).

Es así como el lector accede físicamente al poemario en un doble sentido: con su imaginación, que lo hace moverse en un espacio percibido por medio de su cuerpo virtual, según lo que hemos comprobado anteriormente a partir de las recientes teorías del Embodied Reading (Caracciolo 117); pero, también, con su voz corpórea y su forma única y personal de pronunciar las palabras, aunque en silencio. Veamos cómo ocurre este doble acceso en el poema que abre el libro.

Entonces caímos en Ciudad Fanon como lentos, blanquísimos cuervos sobre un quemado maizal.

Los cánticos del vudú escuchamos, la gorda plegaria de los zambos exiliados de Pernambuco. "Oui missié, oui missié", decían los pequeños cargadores mulatos, y nosotros, al unísono, largamos:

"Mi buen obrero, no mientas nunca, y nunca robes, nunca, nunca...”. (Huenún 2014, 9)

El viaje del cuerpo virtual del lector se ve connotado desde el principio en un fuerte sentido físico-perceptivo por medio de la metáfora de los cuervos pla- 
neando circularmente sobre el maizal quemado. Enseguida, el cuerpo virtual del lector se encuentra inmerso en un paisaje sonoro: cánticos, plegarias, frases escuchadas y frases dichas, que el lector, ahora en su rol de activador de la voz del texto por medio de la suya propia, transforma en signos aurales y de allí en sonidos imaginados (Tadié 109). Sin embargo, el poema no limita su sonoridad a este primer nivel semántico, sino que la actualiza, como dispositivo de reverberación, en la textura sonora del significante, generando una estructura recursiva y circular como la propagación de la onda sonora. Por ejemplo, la nasal velar $/ \eta /$ y la nasal alveolar $/ \mathrm{n} /$, especialmente dotadas de potencial de resonancia debido a su cercanía al campo vocálico y su facilidad por activar los sobre-tonos, están muy presentes en los primeros dos y últimos dos versos del poema, conformando un anillo de expansión sonora. Además, la rima escondida y parcialmente invertida entre "caímos" y "maizal" tensiona subrepticiamente el primer y el tercer verso. Se pone así en movimiento una masa sonora más amplia de lo que los fonemas tomados singularmente dejarían sospechar. En su lectura silente pero no por ello menos sonora, el lector va percibiendo una constelación de ecos que anima el texto poético (Stewarts 69). El poema es una cámara de ecos.

La multiplicación y refracción de los sonidos, típica del fenómeno del eco, se relaciona, a nivel semántico y simbólico, con la colectividad de voces que se dejan escuchar en el poema. Están los fieles del vudú, los zambos, los mulatos y los que se identifican con el "nosotros", posiblemente los opresores si queremos atender a la metáfora de los "blanquísimos cuervos"; todos convocados en la plurivocalidad de la constelación de ecos que el significante se encarga de dejar escuchar. $\mathrm{Al}$ activar la sonoridad potencial contenida en las referencias a sonidos y en las frases pronunciadas en el texto, el lector acerca a su boca la voz de otros. ¿Podemos afirmar que el lector atrae y trae entre sus labios, alrededor de su lengua, dentro de su garganta, hacia sus cuerdas vocales, la voz del otro? ¿Lee con su voz única y singular la unicidad y singularidad de otras voces? ¿Hace espacio en su boca para que se cree una superposición deseada y peligrosa? ¿Accede a la fisura donde ensaya su desborde hacia otra identidad? ¿Finge ser otro, otros hablan en él? ¿Invierte en su boca la imitación y proyección del negro hacia el blanco?

En el análisis de Fanon, el negro cree ser blanco: "Pour le Noir, il n'y a qu'un destin. Et il est blanc" (8). El negro auto-aliena su identidad para adquirir la del blanco, tan alienado como aquel porque no logra verlo sino a través del filtro del racismo. A través de la evocalización del texto de Huenún, el 
lector podría pensar que el poema está permitiendo que en su voz resuenen y se dejen escuchar las verdaderas voces negras, mulatas, indias, que le conceda por un momento asumir su identidad, encaminarse en un destino negro. El lector escucha una voz no pronunciada pero que allí está: tal como lo plantea Roland Barthes, escucha sus índices, como el jaguar escucha el ruido de su presa acercándose o la liebre los pasos del cazador (245). La escucha del lector es una escucha de alerta, define el territorio de lo que conoce, lo familiar, lo apropiado, lo que defiende como propio. Es la escucha que alerta al lector contra incursiones no deseadas y empieza a introducir en su mente una pequeña duda: ¿Son las voces de los zambos y los mulatos su propia voz? ¿Es su voz una voz ajena? El índice que el lector escucha en esa voz, ¿revela un peligro irrumpiendo en su territorio, o bien un desajuste en su imitación del cargador mulato?

El poema, puesto bajo presión por la evocalización y la escucha de los índices, estalla cuando, desde la escucha de la voz de la multitud, el lector se mueve hacia la escucha de la voz de Fanon. El lector descubre que, en el texto Piel negra, máscaras blancas, que Huenún utiliza como hipotexto en su fino trabajo palinséstico, la exclamación "Oui missié, oui missié" aparece citada desde las historietas ilustradas para los niños, donde es inevitablemente pronunciada por los personajes negros (Fanon 27); los últimos dos versos son la inversión de "Moi bon ouvrier, jamais mentir, jamais voler" que Fanon recuerda ser pronunciada por el personaje negro en el filme Sans Pitié (27). El lector se da cuenta de que las frases del poema no le llegan directamente de quien tendría que pronunciarlas en el texto (los cargadores mulatos, sus capataces), sino que vienen de vuelta, refractadas en el estereotipo racista del blanco. El juego de identificación-alienación se le escapa de las manos. La única verdadera voz de la cual el lector debía sospechar era la suya, porque de ella y de su privilegio histórico y racial, así como del círculo de estereotipos construidos para "protegerla" de los otros, muy difícilmente podrá huir.

\section{LA ESCUCHA DE LA VOZ SONORA DEL POETA}

La forma en que los lectores reciben una obra a través de la voz de su autor por medio de una escucha auditiva, transformándose por consiguiente en público, es un aspecto que puede ser pensado como prescindible en la respuesta estética de formas literarias tales como la narrativa. En su clasificación de los tipos de imaginación mental en la lectura, Kuzmičová, coherentemente con su 
campo de investigación, limita a la imaginación verbal a la "speech-imagery", en la cual el lector imagina escuchar el texto pronunciado en voz alta por un narrador o por los personajes mismos, y a la "reharsal-imagery", donde el lector se imagina su propia voz pronunciando el texto, es un "vicarious speaker" (284-86). Sin embargo, la teórica admite que la poesía o la prosa narrativa funcionan de manera diferente, encontrándose en ellas mucho más marcada la experiencia de vocalización y auralización del lenguaje en el proceso de la comprensión y la respuesta estética. Efectivamente, el evento del Reading o lectura pública por parte del poeta muchas veces es parte integrante de la dinámica pragmática de recepción del género poético. Es por eso que un estudio del rol de las sensaciones y de la corporalidad en la respuesta estética en este género literario no puede hacer caso omiso de la actualización del poema en la voz de su autor y de las consecuencias que esto conlleva en la recepción por parte de sus lectores.

La lectura en voz alta va contextualizada dentro de la práctica de la performance, la cual, por una parte, le permite al poeta "refocus emphasis and overlaying inmanent rythms" (Bernstein 145) y, por la otra, "implica una mediación corporal y una intensidad de intercambio energético entre intérprete y audiencia. De allí ese factor ritualizante que la puesta en voz pone a prueba de manera insoslayable, midiendo el alcance poético de la palabra en la propia voz del poeta" (Bravo 11). Es decir, la performance de la lectura de poesía lanza el texto a una nueva dimensión, tanto a nivel creativo -donde el potencial del texto sale a flote junto con sus posibles variaciones-, como a nivel de interacción con el público con quien se va creando una tensión productiva. Como ya observaba Paul Zumthor en su Introducción a la poesía oral, la lectura de la poesía en público exalta el protagonismo explícito del cuerpo, gracias al cual la voz adquiere el espesor y la resonancia de sus órganos y se acompaña de movimientos y gestos (202).

En las performances del autor en ocasión del lanzamiento del libro en 2014 y de lecturas poéticas sucesivas ${ }^{12}$ se podía notar, además del acompañarse recíproco de la emisión vocal y los movimientos del cuerpo, una línea prosódica oscilatoria, aceleraciones y desaceleraciones en la emisión, un aumento y disminución del volumen, una acentuación de consonantes por medio de én-

12. El lanzamiento del libro se realizó, en Santiago, en el Club Social Juan Ramsay en el otoño de 2014. El estudio del aspecto performático y sonoro para efectos de este artículo se llevó a cabo a partir de la grabación de una lectura en contexto privado, en el invierno de 2016. 
fasis o de interrupciones improvisas, una prolongación de las vocales y de las consonantes líquidas, nasales, sibilantes, lo cual hace colindar la dicción poética con el canto. En la explicación de Huenún, su estilo de lectura lleva efectivamente rastros del cancionero popular, de la ranchera (el autor menciona a los cantantes Jorge Negrete, Javier Solís, entre otros), junto con la influencia de la poesía en verso (romance, soneto, décimas) y de la ritmicidad y la línea melódica del habla campesina y pueblerina del sur de Chile, su lugar de proveniencia. ${ }^{13}$

Huenún recuerda cómo fue adquiriendo su notable habilidad oratoria en el bar de su familia, donde solía atender a los parroquianos reunidos a tomar hasta emborracharse y a comentar sucesos grandes y pequeños: siempre abundaban las anécdotas y las historias, declamadas con esmero para que se pudiesen guardar en la memoria oral de los demás. De allí deriva la expresividad y caracterización de lo contado y el cuidado especial que Huenún pone en pronunciar claramente todas las vocales y las consonantes. Huenún aspira a una lectura que "golpee, sacuda, estremezca la atención a partir de la sonorización de las palabras" (Huenún, conversación personal), que capture y seduzca a su público como le ocurrió alguna vez a él cuando, adolescente, asistió a una lectura del poeta Gonzalo Rojas; pero también apunta a una lectura que le permita al público retener algunas expresiones en la memoria, gozar de cierta transparencia del sentido.

Siguiendo con la nomenclatura de los tipos de escucha detallados por Barthes, la voz del autor, con su potencial seductor, relacional, pero también vehicular con respecto al sentido, llama a una escucha de desciframiento (consistente en captar y entender los signos y de allí los significados) y una escucha "transfer", la cual se interesa más en el emisor que en el mensaje, se insinúa en el espacio entre los interlocutores, implícitamente ordena "tócame, entérate que existo" (249), impone "meterse en [el deseo del otro], perder el equilibrio en él, acabar por instalarse en él” (253).

En el poema cuya lectura acabamos de revisar, la escucha de este último tipo, al plantear el deseo por el otro y la preeminencia de la relación, ilumina por contraste la incomprensión de fondo entre el intelectual y la masa. En el

13. Esta y las siguientes informaciones se consiguieron durante la conversación personal con el autor el 7 de julio de 2016. No he logrado encontrar bibliografía específica sobre la relación de la poesía de Huenún con el canto popular de raíz occidental, de manera que el testimonio del poeta es la fuente en que me estoy basando en este artículo. 
poema "Liberamos a Vallejo de la Cárcel" hay una disociación, una distancia insalvable entre la visión de un César Vallejo empolvado y asustado y las motivaciones de sus animosos libertadores, quienes, al no obtener de él la reacción esperada, no tardan ni un segundo en descargar contra él la alegre y casi gímnica violencia con que hacen saltar muros y fortines: "Liberamos a Vallejo de la cárcel / arrojando las granadas que nos diera / el tozudo comandante Abimael. // Se cayeron las murallas, las torretas, / la blindada oficinita del alcaide, / y el templete franciscano del fortín [...] Lo miramos y le dimos en la madre / bajo un sol que rajaba las arenas / justo frente a las huacas de Chan Chan" (Huenún 2014, 28). Por medio de la escucha "transfer", los lectores se enteran más intensamente del deseo frustrado del intelectual por comunicarse con los "condenados" de la tierra, los que nunca tienen voz o se limitan a ser meros ejecutantes, pero también perciben su individualidad herida, su cansancio y renuncia final. Dirá Vallejo en el poema: "Ya no creo en ustedes -nos repuso-, / no son más que una recua de rufianes, / vil calaña de la banda de Guzmán" $(2014,28)$.

También la escucha descifradora resalta la dicotomía entre la voz sola del intelectual y la voz colectiva de las masas. Si, como postula Huenún, el intelectual debe ser el que comunica con claridad la confusión y la incomprensibilidad de los procesos históricos, esa mediación se da por medio de un patrón regular de rimas, metros y acentos, heredado de la tradición oral y comunitaria. El intelectual aprende de los que "no importan", como los campesinos que acudían al bar de su infancia, las estrategias y las herramientas para salir momentáneamente del anonimato y contar una historia que se recuerde. Nuevamente, en la caja de resonancia del poema se hace escuchar el eco y su carga inevitablemente plural, esta vez multiplicado en la voz del autor quien, por medio de la recursividad de los octosílabos, septenarios, dodecasílabos, y de la reverberación sonora de las vocales y consonantes, pone la sensualidad y carnalidad del discurso al servicio de la comprensibilidad. En resumen, la escucha de la voz del autor leyendo su poesía acerca y ata estrechamente entre sí los extremos de la relación entre la voz de las masas y la voz del intelectual (sea este Fanon, Huenún u otro poeta como Vallejo), extremos que en la dualidad detectada en la escucha de la voz silente del lector quedaban posiblemente más lejanos y sueltos.

El autor cierra su libro con un poema que excede aparentemente los límites, por lo menos cronológicos, del hipotexto Piel negra, máscaras blancas, ya que acompaña a Fanon en su último viaje a Estados Unidos en el desesperado 
intento de curarse del SIDA. La presencia fantasmática del numen tutelar del libro se hace carne doliente, cuerpo desamparado y estrictamente fisiológico, dispuesto a abjurar de los ideales y viajar al corazón del país execrado con tal de salvarse. "No vivo ya en mi nombre, camaradas, / el curso de las aguas ha iniciado / el tiempo de otro vuelo, el aire de otro cántico. [...] No vivo ya en mi alma, camaradas, / mi piel no da la luz que la muerte necesita. / Disperso, confundido, / mi canto busca a tientas / la cura de las sombras, / la ley del vaticinio" (Huenún 2014, 43). En la performance analizada para realizar el presente estudio, la voz de Huenún, quien también tuvo en el pasado problemas de salud bastante serios, se volvió particularmente simpatética y afanada en la ejecución de este poema: la voz, aunque muy controlada, colinda en momentos con la respiración y el estertor. Pero el poeta no se deja torcer la mano por la tentación de transmitir una emocionalidad explícita. El texto, en su complejidad, esconde su inteligente doble fondo, como ya se ha visto anteriormente. En él se encuentra incrustado un despido pesaroso y musical "Adieu madras, adieu foulards, / adieu, adieu” (43). En Piel negra, máscaras blancas de Fanon, este pasaje corresponde al ejemplo del negro que se va de la colonia a la capital occidental, percibiéndose ya diferente y algo superior respecto a sus compañeros que lo acompañan al puerto. ${ }^{14}$ Con apiadada compasión hacia su figura inspiradora, pero con desengañada lucidez a la vez, Huenún nos enfrenta al desnudo mecanismo de las identificaciones, desidentificaciones y alienaciones en que parece finalmente caer Fanon en sus últimos días.

En definitiva, lo que el microcosmos de Ciudad Fanon pretende transparentar a través de la resonancia cruzada y contradictoria de todas estas voces es el inevitable fracaso histórico de los grandes proyectos ideológicos, educativos, higiénicos, políticos, civilizatorios impuestos a las masas latinoamericanas. El libro muestra cómo la pluralidad de sujetos que el intelectual contempla, sin

14. A su vez, Fanon posiblemente se refiriera a la canción "Adieu Foulard, Adieu Madras", atribuida a François Claude de Bouillé, quien fue gobernador de la Guadelupe, un archipiélago de las Antillas bajo dominio francés, durante parte del siglo XVIII. La canción, en creole, habla del melancólico alejarse de la isla con la nave. Fanon resignifica la canción en los siguientes términos: "Il y a une sorte d'envoûtement à distance, et celui qui part dans une semaine à destination de la Métropole crée autour de lui un cercle magique où les mots Paris, Marseille, la Sorbonne, Pigalle représentent les clés de voûte. Il part et l'amputation de son être disparait à mesure que le profil du paquebot se précise. Il lit sa puissance, sa mutation, dans les yeux de ceux qui l'ont accompagné. «Adieu madras, adieu foulard...». Maintenant que nous l'avons conduit au port, laissons-le voguer, nous le retrouverons. Pour l'instant, allons à la rencontre de l'un d'entre eux qui revient. Le «débarqué», dès son premier contact, s'affirme; il ne répond qu'en français et souvent ne comprend plus le créole" (18). 
alcanzar a comprenderla, está siguiendo como mejor puede su propio destino, independiente de líderes y mandatos externos que agoten el significado de su existencia y rol histórico. Los habitantes de Ciudad Fanon se equivocan, luchan y caen sin necesidad de que un intelectual los una en una fraternidad mística más funcional a sus sueños políticos que al beneficio de aquellos. Como nos recuerda el filósofo italiano Stefano Visentin, "Fanon rifiuta di considerare la lotta dei popoli neri come un modello universale; quello fanoniano è necessariamente un universalismo situato, costituito da rivendicazioni parziali e concrete" (86). Más bien, se trataría de pensar que la nomadía, el desengaño, la violencia, el arrepentimiento, el despojo y la incertidumbre sufridos a lo largo de los siglos por estas comunidades e individuos, se complementan con el potencial positivo y constructivo de la diferencia, la contradicción y la autonomía, de acuerdo a lo planteado por Fanon: "Je ne suis pas prisionner de l'Histoire. Je ne dois pas chercher le sens de ma destinée. Je dois me rappeler à tout instant que le véritable saut consiste à introduire l'invention dans l'existence. Dans le monde où je m'achemine, je me crée interminablement" (186).

\section{CONCLUSIONES}

El estudio de los poemarios Puerto Trakl y Fanon City Meu desde la recepción lectora, tanto imaginativo-perceptiva como vocal, permite apreciar las dinámicas de identificación y des-identificación vivenciadas por una parte de los sujetos productores y consumidores del discurso social y cultural: lectores educados en la cultura occidental, acostumbrados a no ver contradicho su etnocentrismo con la misma frecuencia como le ocurre a otras civilizaciones. En el caso de Puerto Trakl, queda al descubierto el límite literario-cultural de identificación y auto-reconocimiento por parte de ese lector: aunque extraordinariamente rico en obras maestras, el canon occidental no pasa de ser una de las muchas formas de narrar y percibir la realidad. Fanon City meu, por otro lado, visibiliza en contexto chileno la línea (racial y racista) del color, que normalmente se encuentra encubierta por el concepto de clase social o etnicidad. El poemario pone a ese lector frente a su doble prejuicio racial, condensado en la aparente contradicción entre la facilidad con que él se larga a identificarse con la "diversidad" cuando esta se ubica en un lugar de-potenciado y su dificultad en aceptar que puede no haber un lugar de preeminencia "naturalmente" reservado para él, en tanto intelectual o líder político, dentro de los fenómenos históricos protagonizados por las masas "subalternas". 
El poema concebido como "cámara de espejos" y "caja de resonancia" permite pensar en una potencialidad ínsita en la poesía de Huenún y posiblemente otros autores, como él conscientemente ubicados en una posición ideológica mestiza: la de desenmascarar con sutileza e inteligencia las implicaciones culturales de la identificación en la lectura.

\section{OBRAS CITADAS}

Barthes, Roland. Lo obvio y lo obtuso: imágenes, gestos y voces. Barcelona: Paidós, 1986.

Bernini, Marco, y Marco Caracciolo. Letteratura e scienze cognitive. Roma: Carrocci, 2013.

Bernstein, Charles. "Hearing Voices". The Sound of Poetry / The Poetry of Sound. Eds. Marjorie Perloff y Craig Dworkin. Chicago: The Chicago UP, 2009. 142-48.

Bravo, Luis. "La puesta en voz de la poesía, antigua arte multimedia". Academia.edu (2011): 1-17. 12 de abril de 2016. <https://www.academia.edu>.

Caracciolo, Marco. "The Reader's Virtual Body: Narrative Space and its Reconstruction". Storyworlds 3 (2011): 117-19.

Cavarero, Adriana. A più voci: Filosofia dell'espressione vocale. Milano: Feltrine1li, 2010.

Damasio, António. The Feeling of What Happens: Body and Emotion in the Making of Consciousness. New York: Harcourt Brace, 2000.

Fanon, Frantz. Peau blanche masques blancs. Paris: Seuil, 1952.

Huenún, Jaime. Puerto Trakl. Santiago: Lom, 2001.

Huenún, Jaime. Fanon City Meu. Santiago: Das Kapital, 2014.

Huenún, Jaime. "El viaje de la luz: entrevista a Jaime Huenún”. Afpunmapu / Fronteras / Borderlands. Poética de los confines: Chile-México. Eds. Tatiana Calderón y Edith Mora. Valparaíso: Ediciones universitarias de Valparaíso, 2015. 221-36.

Iser, Wolfgang. The Act of Reading: A Theory of Aesthetic Response. Baltimore: Johns Hopkins, 1978.

Jahn, Manfred. "More Aspects of Focalization: Refinements and Applications". GRAAT 21 (1999): 85-110.

Kuzmičová, Anežka. "Literary Narrative and Mental Imagery: A View from Embodied Cognition”. Style 48.3 (2014): 275-93.

Lakoff, George, y Mark Johnson. Philosophy in the Flesh: The Embodied Mind and Its Challenge. New York: Basic Books, 1999. 
Mansilla, Sergio. "«Palabras que van a dar al río de una poesía inútil»: una aproximación a la poética de Jaime Huenún a partir de Puerto Trakl". Alpha 32 (2001): 11-27.

Minsky, Marvin. “A Framework for Representing Knowledge”. The Psychology of Computer Vision. Ed. Patrick Winston. New York: McGraw Hill, 1975. 211-77.

Mora Curriao, Maribel. "Poesía Mapuche del siglo Xx: escribir desde los márgenes del campo literario". Historia, colonialismo y resistencia desde el país mapuche. Ta Iñ Fijke Xipa Rakizuameluwün. Eds. Vv. AA. Santiago: Ediciones comunidad de historia mapuche, 2012. 305-39.

Ryan, Marie-Laure. Narrative as Virtual Reality: Inmersion and Interactivity in Literature and Electronic Media. Baltimore/London: John Hopkins UP, 2001.

Stewarts, Garret. Reading Voices: Literature and the Phonotext. California: California UP, 1990.

Syrotinski, Michael, e Ian Maclachlan, eds. Sensual Reading: New Approaches to Reading in Its Relations to the Senses. London: Associated UP, 2001.

Tadié, Alexis. "From the Ear to the Eye: Perceptions of Language in the Fictions of Laurence Sterne". Sensual Reading: New Approaches to Reading in Its Relations to the Senses. Eds. Michael Syrotinski e Ian Maclachlan. London: Associated UP, 2001. 106-23.

Varela, Francisco, Evan Thompson y Eleanor Rosch. The Embodied Mind: Cognitive Science and Human Experience. Massachussets: MIT Press, 1991.

Visentin, Stefano. "Trasformazioni della Verwandlung: Rileggere l'accumulazione originaria attraverso Fanon". Fanon postcoloniale. Ed. Miguel Mellino. Verona: Ombre corte, 2013. 75-88.

Zumthor, Paul. Introducción a la poesía oral. Madrid: Taurus, 1991.

Zwaan, Rolf. "The Immersed Experiencer: Towards an Embodied Theory of Language Comprehension". Psychology of Learning and Motivation 44 (2003): 34-62. 